\title{
Effect of a Multifaceted Intervention on Hand Hygiene Compliance among Healthcare Workers at the Medicine Wards and ICU in a Tertiary Hospital Setting
}

\author{
Rich Ericson C. King ${ }^{1}$ and Regina P. Berba ${ }^{2}$ \\ ${ }^{1}$ Department of Medicine, Philippine General Hospital, University of the Philippines Manila \\ ${ }^{2}$ Department of Medicine, College of Medicine and Philippine General Hospital, University of the Philippines Manila
}

\begin{abstract}
Background. While hand hygiene is recognized as the cornerstone for reducing risk for nosocomial infections, compliance in our institution remains low. Previously identified barriers include poor access to hand hygiene products, lack of reminders, and poor knowledge on indications.
\end{abstract}

Methods. At the medical wards and ICU of a tertiary hospital, a group of medical students, residents, and nurses was exposed to interventions addressing the identified barriers. Alcohol handrub was provided at each bedside, visual reminders were placed at critical locations, and commonly missed opportunities were reinforced at the start of the study. Hand hygiene compliance was covertly evaluated after two weeks and compared against that of an unexposed group.

Results. 664 and 727 hand hygiene opportunities were observed in the unexposed and exposed groups, respectively. Compliance was higher in the exposed group ( $32.60 \%$ vs. $16.26 \%, p<0.05$ ), which by subset analysis was consistent for the different healthcare worker designations and locations evaluated. Nurses had the highest compliance rate in both groups.

Conclusions. These results suggest the efficacy of the employed interventions in improving hand hygiene compliance in this setting. Hand hygiene opportunities identified to be most frequently missed in this observation can guide future intervention efforts in our institution.

Key Words: hand hygiene, hand hygiene compliance, infection control

\section{INTRODUCTION}

Health care-associated infections (HCAI) cause a substantial burden in hospital, ambulatory and long-term care settings worldwide. While high-quality data is scarce, pooled prevalence data show that HCAI occur in 15.5 per 100 patients in resource-limited settings. ${ }^{1}$ In addition to increased mortality and cost, HCAI also contributes to prolonged hospital stay, long-term disability, and increased microbial resistance. ${ }^{2}$

Transmission of healthcare-associated pathogens occurs during routine patient care. These pathogens are found not only in body fluids and infected wounds, but also in intact skin.

Corresponding author: Rich Ericson C. King, MD Department of Medicine Philippine General Hospital

University of the Philippines Manila

Taft Avenue, Ermita, Manila 1000 Philippines

Telephone: +639338547598

Email: richericson.king@gmail.com
In addition, the continuous shedding of squames also allow for the contamination of the patient's immediate environment. Contact with the patient and his/her environment therefore exposes healthcare workers to contamination. ${ }^{3}$ Hand hygiene effectively reduces hand contamination and transmission of pathogens, making it the cornerstone of $\mathrm{HCAI}$ risk reduction. ${ }^{4}$ 
In line with this, the World Health Organization (WHO) in 2009 recommended the five moments of hand hygiene: (1) before patient contact, (2) before an aseptic task, (3) after body fluid exposure risk, (4) after patient contact, and (5) after contact with patient surroundings. Hand hygiene opportunities represent instances during patient care wherein hand hygiene should be performed due to the presence at least one of these indications. Understandably, there may be instances wherein more than one hand hygiene indication exists for a given opportunity. ${ }^{5,6}$

Alcohol-based hand rub has a higher efficacy in reducing the viable microbial load on hands compared to antimicrobial soaps and even more so to plain soaps. ${ }^{5,7}$ Use of hand rub allows for the performance of hand hygiene right at the point of care. Additionally, due to its rapid efficacy, use of hand rub takes a shorter time to complete (20-30 seconds) in contrast to handwashing (40-60 seconds). For these reasons, use of alcohol-based hand rub is the preferred method of performing hand hygiene for most indications, except when hands are visibly dirty or visibly soiled with blood or body fluids, after toilet use, or when exposure to spore-forming microbes such as Clostridium difficile is suspected. ${ }^{5}$ Moreover, the relative ease of use for hand rubs has been demonstrated to result in a significant improvement in compliance among healthcare workers. ${ }^{8,9}$

Numerous studies associate improvements in hand hygiene practices among healthcare workers with reduced incidence of HCAI. Allegranzi and Pittet summarized hand hygiene intervention efforts published between 1977 and 2008 and demonstrated that various interventions led to significantly decreased rates of HCAI in 16 out of 24 studies. ${ }^{4}$ However, compliance of healthcare workers to hand hygiene protocols remain unacceptably low in most institutions, falling below $50 \%$ of hand hygiene opportunities in most hospitals. ${ }^{10} \mathrm{~A}$ recent observational study conducted in the Philippine General Hospital showed that overall hand hygiene compliance by healthcare workers in the medical wards and intensive care unit was $10.6 \%$. This was despite providing lectures and training and years of hospital-wide campaigns promoting hand hygiene. In addition, while majority recognize its importance, only $15 \%$ of healthcare workers knew all five hand hygiene indications. Major barriers identified in the study included the lack of sinks, hand hygiene products, and hand hygiene reminders, as well as high hand hygiene workload. ${ }^{11}$

\section{Rationale of the study}

In the Philippine General Hospital, despite acceptance among healthcare workers of the importance of hand hygiene, compliance to hospital hand hygiene protocol remains unacceptably low. Previously identified barriers include those that may be addressed with only minimal cost. These include poor access to hand hygiene products at the site of care, lack of hand hygiene reminders, and lapses in knowledge among healthcare workers regarding indications of hand hygiene. Because multiple factors contribute to noncompliance, a multifaceted approach is warranted in order to improve hand hygiene practices. This is a follow-up study to assess hand hygiene compliance among healthcare workers exposed to interventions implemented by the investigators and the PGH Infection Control Unit addressing previously identified barriers.

\section{Objective}

To compare the hand hygiene compliance rate in the Medicine wards and intensive care unit between healthcare workers exposed and unexposed to a directed, multifaceted intervention addressing previously identified barriers.

\section{METHODS}

\section{Study type}

Hand hygiene practices of the study population were evaluated by direct observation using a quasi-experimental study design. A prospective cohort would have been more desirable to allow a better comparison between groups. However, the nature of the intervention and the working setup in the study setting precludes the isolation of a control group from an intervention group.

\section{Setting}

The study was conducted in the Philippine General Hospital, a tertiary teaching hospital administered by the University of the Philippines System. In particular, interventions and evaluations were limited to the Medicine wards (Ward 1 and Ward 3) and Medical Intensive Care Unit (MICU). The study setting was chosen based on a previous evaluation in this setting showing very low hand hygiene compliance rates among healthcare workers, prompting the Hospital Infection Control Unit to launch an intensified hand hygiene promotion campaign.

\section{Intervention}

The multifaceted intervention involved structural and cognitive strategies aimed at the different healthcare workers in the study setting, namely first year residents, nurses, and medical students. The goal of the intervention was to foster an environment that is supportive of hand hygiene compliance.

Lack of access to hand hygiene products was addressed by providing alcohol-based hand rub at the foot of each bed in Wards 1 and 3 and in the MICU. These were secured in placeholders to prevent displacement and regularly checked for malfunction. Replenishment of stocks of alcohol hand rub was facilitated with the help of local hospital staff. The availability of clean hand towel and soap at designated sinks was also ensured. Hand hygiene reminders in the form of posters elaborating the five moments of hand hygiene were displayed at high-visibility locations in the ward and MICU.

Hand hygiene was further encouraged by reinforcing hand hygiene indications, proper hand hygiene technique, 
common lapses in hand hygiene, and presenting recent hospital data on HCAI during orientation prior to rotating in the Medicine wards and ICU.

\section{Observational survey}

The observation and data gathering method previously utilized by Gaboy and Berba during the initial evaluation was retained in this study. Observations were distributed equally among three different time shifts- morning (6am to $12 \mathrm{nn}$ ), afternoon (12nn to $6 \mathrm{pm}$ ), and night (6pm to $6 \mathrm{am}$ ), and among three locations - Ward 1, Ward 3, and the Medical ICU. Observations were performed for two hours per shift and were conducted in the appropriate ratio of weekdays to weekends $(5: 2)$. This was to ensure that hand hygiene opportunities occurring at different times and days were accounted for in their appropriate relative frequencies.

Hand hygiene compliance was evaluated by conducting an observational survey of the determined appropriate number of hand hygiene opportunities. Observation was first done on a group of healthcare workers while unexposed to the intervention, then two weeks after implementation of the planned intervention, on a different group of healthcare workers to represent the exposed group. This was done because the nature of the intervention precludes targeting exposure to only a specific subpopulation of healthcare workers. Because nurses are present in the study setting throughout the year, they were randomly allocated to be observed to either with or without the intervention. On the other hand, doctors and students only transiently serve in the study setting for four weeks at a time; hence discrete groups of exposed and unexposed healthcare workers can be isolated. Essentially, healthcare workers included in the unexposed group were excluded from post-intervention observation.

The subjects were kept unaware of the hand hygiene evaluation throughout the duration of the study. Random convenience sampling was used in observing healthcare workers doing routine patient care, and was done as discreetly and as far away as possible. At most two hand hygiene opportunities were observed at any time. Importantly, observations were limited to hand hygiene opportunities during standard patient care and did not include those during emergency medical treatment (such as during cardiopulmonary resuscitation and endotracheal intubation).

Hand hygiene was assessed using the methodology prescribed in the 2009 Hand Hygiene Technical Reference Manual from the World Health Organization. Each hand hygiene opportunity observed was treated as one sample, regardless of the number of indications that exist for that opportunity. For each opportunity encountered, the observer noted the applicable indications present, and hand hygiene action, whether by hand washing with soap and water, or use of an alcohol-based hand rub. Hand hygiene actions observed at instances wherein no indication exists were not considered hand hygiene opportunities and were thus not included. Other variables to be noted for each sample include healthcare worker designation and location. Variables evaluated in the previous study but determined to have no significant impact on compliance, namely time of day, day of week, and glove use, were no longer evaluated in this study. Data obtained were recorded in a coded data sheet as seen in Appendix.

\section{Sample size determination}

The number of hand hygiene opportunities to be observed was based on the latest historical compliance rate data obtained for the study setting. Using a confidence level of $95 \%$, margin of error of $5 \%$, obtained baseline overall compliance rate of $10.9 \%$, and increasing by $5 \%$ to account for contingencies such as recording error, a minimum of 157 hand hygiene opportunities were needed to be observed by random convenience sampling to detect a significant change in overall compliance rate. Because changes in compliance rate were also intended to be assessed separately for each professional status, giving 3 total subsets of the study population, at least 471 hand hygiene opportunities were needed to be observed in total for the evaluation of the unexposed group. The obtained compliance rate in the unexposed group was used to determine the sample size needed for the exposed group.

\section{Data analysis}

Compliance rate was obtained by taking the ratio of the number of observed hand hygiene actions to the number of observed opportunities, as represented in the formula: Compliance $(\%)=$ [performed actions] / [opportunities] x 100 .

Overall compliance rate was compared between the unexposed and exposed groups using $\chi^{2}$ test with corresponding 95\% confidence interval. Likewise, subset analysis was also performed, comparing compliance in the two groups by specified professional status, location and hand hygiene indication.

Difference in preference for method of hand hygiene was also evaluated by comparing the relative frequencies of handwashing with soap and water and use of alcohol hand rub. The $\chi 2$ test was used with corresponding $95 \%$ confidence interval to detect any significant difference between the two groups. All statistical analyses were conducted using Microsoft Excel 2010 and Stata 10.0 for Windows.

\section{RESULTS}

\section{Observation survey}

A total observation period of 72 hours was conducted, equally divided between the unexposed and exposed groups, and between the two Medicine wards and ICU. This yielded a total of 664 hand hygiene opportunities observed in the unexposed group and 727 opportunities observed in the exposed group. The mean number of opportunities observed per session was 38. Table 1 summarizes the composition of the study population and observed opportunities by professional status. Nurses comprised the largest number 
Table 1. Composition of HCWs by designation in the study setting and observed opportunities per HCW

\begin{tabular}{cccc} 
Designation & Number & $\begin{array}{c}\text { Opportunities } \\
\text { observed }\end{array}$ & $\begin{array}{c}\text { Opportunities } \\
\text { per HCW }\end{array}$ \\
Student & 48 & 712 & 15 \\
Nurse & 60 & 440 & 7 \\
Doctor & 21 & 239 & 11 \\
\hline Overall & 129 & 1391 & 11 \\
\hline
\end{tabular}

among healthcare workers, while students had the highest number of opportunities observed. An average of 11 hand hygiene opportunities were observed per healthcare worker.

Table 2 below shows that there was no significant difference between the two groups in terms of the distribution of observations by location and by indication present. By professional status, nurses comprised a higher percentage of observed opportunities in the exposed group than in the unexposed group, while the proportion of students and doctors observed in the two groups did not differ significantly.

Overall hand hygiene compliance was significantly higher in the group exposed to the intervention compared to the unexposed group (32.60\% vs. $16.27 \%$; $p$ value $<0.0001)$. Both handwashing and use of alcohol hand rub were performed more frequently in the exposed group compared to the unexposed group ( $\mathrm{p}$ value 0.0006 and $<0.0001$, respectively). In the group exposed to the intervention, hand hygiene was performed more frequently with alcohol hand rub than with soap and water (Figure 1).

Subset analysis demonstrated that the significant difference in hand hygiene compliance between the two groups is consistently present for all HCW designations, locations and for three hand hygiene indications (Table 3). The study, however, failed to demonstrate a difference in compliance before aseptic procedures and after body fluid exposure risk. Nurses had the highest $\mathrm{HH}$ compliance rate among all HCWs with or without the intervention. The difference in compliance rate was highest among nurses as well.

The significant difference in hand hygiene compliance between the two groups is also consistently present for all locations. However, a significant difference was seen for only three hand hygiene indications. The study failed to demonstrate a difference in compliance before aseptic procedures and after body fluid exposure risk ( $\mathrm{p}$ value 0.5835 and 0.1416 , respectively).

Table 2. Comparison of select characteristics of hand hygiene opportunities observed between populations unexposed and exposed to a hand hygiene intervention

\begin{tabular}{lccc} 
& \multicolumn{2}{c}{ Opportunities } & \multirow{2}{*}{ Chi square p-value } \\
\cline { 2 - 3 } Professional status & Unexposed group $\mathrm{n}(\%)$ & Exposed group n (\%) & \\
$\quad$ Student & $349(52.56)$ & $363(49.93)$ & 0.3272 \\
Nurse & $189(28.46)$ & $251(34.53)$ & 0.0151 \\
Doctor & $126(18.98)$ & $113(15.54)$ & 0.0900 \\
\hline Location & & & 0.9326 \\
Ward 1 & $238(35.84)$ & $259(35.63)$ & 0.4413 \\
Ward 3 & $201(30.27)$ & $234(32.19)$ & 0.5010 \\
MICU & $225(33.89)$ & $234(32.19)$ & 0.8143 \\
\hline Indication & & & 0.3781 \\
Before patient contact & $279(42.02)$ & $310(42.64)$ & 0.1446 \\
Before aseptic technique & $36(05.42)$ & $32(04.40)$ & 0.2268 \\
After body fluid exposure risk & $51(07.68)$ & $72(09.90)$ & 0.1156 \\
After patient contact & $300(45.18)$ & $352(48.42)$ & $204(28.06)$ \\
$\quad$ After contact with patient surroundings & $212(31.93)$ & & \\
\hline
\end{tabular}

Table 3. Comparison of hand hygiene compliance by category between groups unexposed and exposed to a multifaceted intervention in the Philippine General Hospital Medicine wards and ICU

\begin{tabular}{|c|c|c|c|c|}
\hline & $\begin{array}{l}\text { Unexposed group actions/ } \\
\text { opportunity (compliance [\%]) }\end{array}$ & $\begin{array}{c}\text { Exposed group actions/ } \\
\text { opportunity (compliance [\%]) }\end{array}$ & $\begin{array}{c}\Delta \text { Compliance } \\
{[\%]}\end{array}$ & $\begin{array}{l}\text { Chi square } \\
\text { p value }\end{array}$ \\
\hline \multicolumn{5}{|l|}{ HCW designation } \\
\hline Student & $36 / 349(10.32)$ & $67 / 363(18.46)$ & 8.14 & 0.0020 \\
\hline Nurse & $56 / 189(29.63)$ & $137 / 251(54.58)$ & 24.95 & $<0.0001$ \\
\hline Doctor & $16 / 126(12.70)$ & $33 / 113(29.20)$ & 16.5 & 0.0016 \\
\hline \multicolumn{5}{|l|}{ Location } \\
\hline Ward 1 & $25 / 238(10.50)$ & $73 / 259(28.19)$ & 17.69 & $<0.0001$ \\
\hline Ward 3 & $30 / 201$ (14.93) & $62 / 234(26.50)$ & 11.57 & 0.0032 \\
\hline MICU & $53 / 225(23.56)$ & $102 / 234(43.59)$ & 20.03 & $<0.0001$ \\
\hline \multicolumn{5}{|l|}{ Indication } \\
\hline Before patient contact & $30 / 279(10.75)$ & $61 / 310(19.68)$ & 8.93 & 0.0028 \\
\hline Before aseptic procedure & $4 / 36(11.11)$ & $5 / 32(15.63)$ & 4.52 & 0.5835 \\
\hline After body fluid exposure risk & $14 / 51(27.45)$ & $29 / 72(40.28)$ & 12.83 & 0.1416 \\
\hline After patient contact & $68 / 300(22.67)$ & $146 / 352(41.48)$ & 18.81 & $<0.0001$ \\
\hline After contact with patient surroundings & $17 / 212(8.02)$ & $55 / 204(26.96)$ & 18.92 & $<0.0001$ \\
\hline Overall & $108 / 664(16.27)$ & $237 / 727(32.60)$ & 16.33 & $<0.0001$ \\
\hline
\end{tabular}




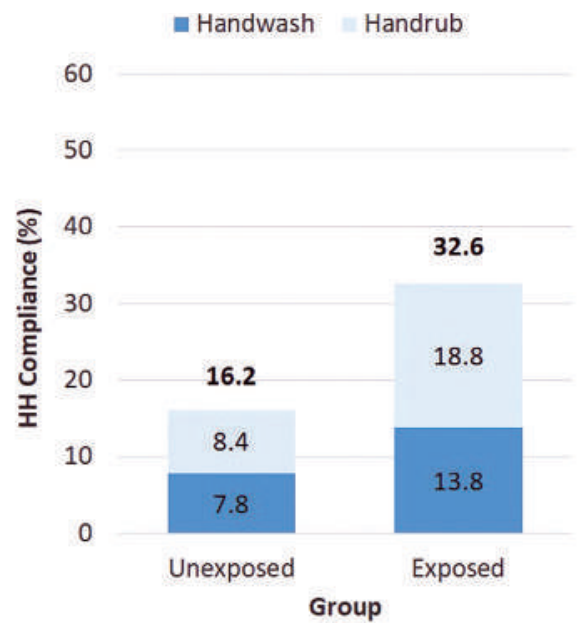

Figure 1. Compliance and choice method of hand hygiene among HCWs unexposed and exposed to a campaign promoting use of alcohol hand rub.

The most frequently missed indications differed between the two groups as well. Hand hygiene after contact with the patient's surroundings was the most frequently missed indication in the unexposed group, followed by before patient contact. In the exposed group, $\mathrm{HH}$ before aseptic procedure and before patient contact were the most frequently missed indications, while hand hygiene after contact with the patient's surroundings had the greatest difference in compliance between the two groups.

\section{DISCUSSION}

Lack of hand hygiene products, hand hygiene reminders, and inadequate knowledge on hand hygiene indications were previously identified as significant modifiable barriers to compliance in the PGH Medicine wards and ICU. In this study, we demonstrated that a multifaceted intervention addressing these barriers was associated with a significantly higher compliance rate compared to no intervention, suggesting its efficacy in improving hand hygiene compliance.

The two groups were similar for all characteristics analyzed, except for the proportion of observed hand hygiene opportunities involving nurses which was slightly but significantly higher in the exposed group. This was probably due to a hospital policy initiated in the middle of the observation period delegating to nurses the task of vital signs monitoring of certain patients. Despite this, the impact of the intervention on hand hygiene compliance is certain, considering its magnitude and its consistency for all designations and locations. We failed to demonstrate a significant increase in compliance for two indications (before aseptic procedure and after body fluid exposure risk), probably due to the small number of samples obtained for these indications.

One limitation of the study was that it would be impossible to estimate the relative contributions of each intervention on the observed improvement in hand hygiene compliance. From an academic perspective it would have been more desirable if only one specific intervention was implemented at a time, in order for us to more properly estimate its impact. However, working with limited resources and keeping in mind the primary objective of improving compliance in the study setting, we opted to address all identified barriers.

Given that both handwashing and use of hand rub increased with the intervention, it can be surmised that both the structural intervention (bedside alcohol hand rub) and cognitive intervention had their own contributions to the improvement in compliance. In addition, hand hygiene after contact with patient surroundings, having the greatest absolute increase in compliance among all the indications, may have improved due to being reported as a common lapse in compliance during staff lectures.

Despite this significant improvement, however, compliance even with the intervention remained very lowroughly only one-third of opportunities. This suggests that still other barriers to compliance may exist that have not yet been explored or addressed. Moreover, future intervention efforts can use information obtained from this observation, such as in identifying specific populations that may require more intensive interventions (students) and identifying commonly missed indications as part of future cognitive intervention strategies.

\section{Biases and limitations}

Because direct observation was used in evaluating compliance, there is an inherent risk for observer bias. This was minimized by strict adherence to the methodology prescribed in the 2009 Hand Hygiene Technical Reference Manual from the World Health Organization. Moreover, only one person conducted the observation throughout the duration of the study. Having only one observer eliminated noise from inter-observer variability. However, this was performed by the principal investigator himself due to financial limitations.

Hand hygiene compliance rate that will be obtained represents an evaluation of compliance in the Medicine wards and ICU only, and cannot be used to estimate compliance in other units or in the hospital as a whole. Proper technique in performance of hand hygiene was not assessed. However, the cognitive intervention implemented included education on proper handwashing technique and use of alcohol hand rub.

As previously mentioned, individual contributions of the different interventions employed cannot be estimated. Nevertheless, it is widely accepted that durable improvements in hand hygiene habits can only be achieved by concurrently addressing the multiple existing barriers to compliance.

\section{Ethical considerations}

The intervention implemented and observational survey was conducted with permission from the Office of the Chairman of the Department of Medicine of the Philippine General Hospital. Anonymity of the healthcare workers 
evaluated was ensured by not including any identifying information (such as name or ID number) in the observation and survey forms. Only healthcare worker designation was recorded in the data collection forms as determining the compliance of individual personnel is not part of the objectives of the study. Moreover, the data collection form was accomplished using a coding scheme in order to deter possible interpretation by overlooking individuals. Once encoded in a working spreadsheet for analysis, the data collection forms were discarded properly to prevent possible recovery by other personnel. Hand hygiene compliance of individual healthcare workers will not be divulged or reported in any form, and only aggregate compliance rate of the study population was reported.

Data gathering activities were conducted as unobtrusively as possible, hence these activities are not expected to compromise patient care or pose health risks to the study population. Moreover, the covert nature of the observation of a public activity such as routine patient care allows for consent for the observational survey to be waived. ${ }^{12}$ Results observational survey, the public will be notified through the hospital infection control unit that an evaluation of hand hygiene practices was done.

Results of the study will be used to formulate recommendations for improvements and planning of future hand hygiene promotion campaigns in the hospital.

\section{CONCLUSIONS AND RECOMMENDATIONS}

Lack of hand hygiene products, hand hygiene reminders, and inadequate knowledge of hand hygiene indications have been identified as contributory factors to the very low compliance rate in the PGH Medicine wards and ICU. Implementing an intervention addressing these barriers has resulted in a doubling of overall compliance rate, and this improvement was demonstrated for all healthcare worker designations and all locations involved. Nurses had the greatest improvement and highest compliance after the intervention, while students had the lowest.

In order for this improvement to be sustained, continuous supply of hand hygiene product should be ensured, and cognitive interventions should be implemented regularly in this setting where there is a high flux of health care workers. This is especially true for students, who comprise the majority of hand hygiene opportunities but at the same time demonstrate the poorest hand hygiene practices among healthcare worker groups. Students spend only at most six weeks in the study setting, but interventions should in fact be integrated even before the start of clinical work in their earlier years of medical school. Compliance should be evaluated periodically and reported in order to serve as feedback to the staff regarding their performance and to provide as a goal for the staff to target.

Hand hygiene compliance may be improved not only by increasing the frequency of hand hygiene action but also by limiting hand hygiene opportunities as well. This can be done by avoiding unnecessary contact particularly with the patient's environment, which was frequently observed as a frequent setting for non-compliance, such as during service rounds.

Despite the documented improvement compared to baseline, hand hygiene compliance in the study setting is still quite low. Improving compliance in the workplace requires a thorough understanding of enabling factors and barriers to compliance. The high hand hygiene workload in the study setting has been demonstrated to be a barrier to compliance, although this is closely linked to financial and logistic limitations that are difficult to address in this resourcelimited setting. Other possible barriers may exist that have to be explored so that an appropriate intervention can be implemented in the future.

\section{Statement of Authorship}

All authors have approved the final version submitted.

\section{Author Disclosure}

All the authors declared no conflict of interest.

\section{Funding Source}

This paper was partially funded by the Philippine General Hospital and the authors.

\section{REFERENCES}

1. Allegranzi B, Bagheri Nejad S, Combescure C, et al. Burden of endemic health-care-associated infection in developing countries: systematic review and meta-analysis. Lancet. 2011; 377(9761):228-41.

2. World Health Organization. Report on the burden of endemic health care-associated infection worldwide: a systematic review of the literature. Geneva, Switzerland: WHO Press; 2011.

3. Khodavaisy S, Nabili M, Davari B, Vahedi M. Evaluation of bacterial and fungal contamination in the health care workers' hands and rings in the intensive care unit. J Prev Med Hyg. 2011; 52(4):215-8.

4. Allegranzi B, Pittet D. Role of hand hygiene in health care-associated infection prevention. J Hosp Infect. 2009; 73(4)305-15.

5. World Health Organization. WHO guidelines on hand hygiene in health care. Geneva, Switzerland: WHO Press; 2009.

6. World Health Organization. Hand hygiene technical reference manual. Geneva, Switzerland: WHO Press; 2009.

7. The Joint Commission. Measuring hand hygiene adherence: overcoming the challenges. Illinois, USA: The Joint Commission; 2009.

8. Girou E, Loyeau S, Legrand P, Oppein F, Brun-Buisson C. Efficacy of handrubbing with alcohol based solution versus standard handwashing with antiseptic soap: randomised clinical trial. BMJ. 2002; 325(7360):362.

9. Hugonnet S, Perneger TV, Pittet D. Alcohol-based handrub improves compliance with hand hygiene in intensive care units. Arch Intern Med. 2002; 162(9):1037-43.

10. Cummings KL, Anderson DJ, Kaye KS. Hand hygiene non-compliance and the cost of hospital-acquired methicillin-resistant Staphylococcus aureus infection. Infect Control Hosp Epidemiol. 2010; 31(4):357-64.

11. Gaboy A, Berba R. Hand hygiene compliance among PGH healthcare workers at the Medicine wards and ICU. Philipp J Intern Med. 2017;55:3.

12. Reyes MV, de Castro LD, Manalastas RM, et al. National ethical guidelines for health research. Philippines: Philippine Health Ethics Research Board; 2011. 
Appendix. Observation Form ${ }^{6}$

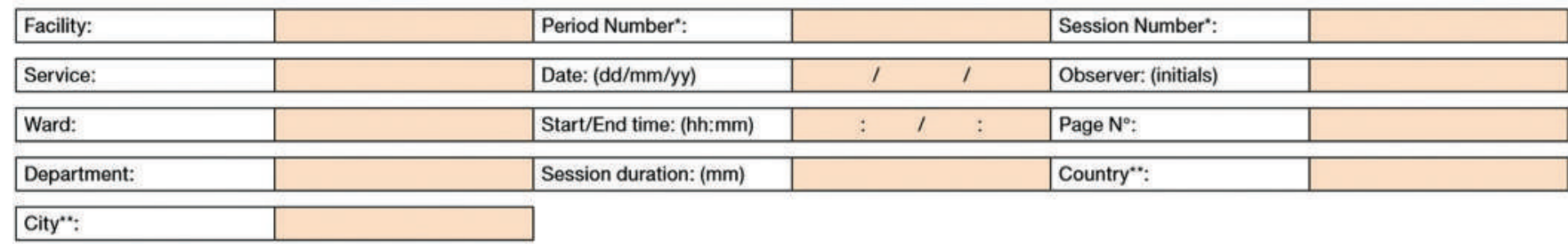

\begin{tabular}{|c|c|c|c|c|c|c|c|c|c|c|c|}
\hline Prof.cat & & & Prof.cat & & & Prof.cat & & & Prof.cat & & \\
\hline Code & & & Code & & & Code & & & Code & & \\
\hline $\mathbf{N}^{\circ}$ & & & $\mathbf{N}^{\circ}$ & & & $\mathrm{N}^{\circ}$ & & & $\mathrm{N}^{\circ}$ & & \\
\hline Opp. & Indication & HH Action & Opp. & Indication & HH Action & Opp. & Indication & HH Action & Opp. & Indication & HH Action \\
\hline 1 & $\begin{array}{l}\square \text { bef-pat. } \\
\square \text { bef-asept. } \\
\square \text { aft-b.f. } \\
\square \text { aft-pat. } \\
\square \text { aft.p.surr. }\end{array}$ & $\begin{array}{l}\square \text { HR } \\
\square \text { HW } \\
\text { O missed } \\
\text { gloves }\end{array}$ & 1 & $\begin{array}{l}\square \text { bef-pat. } \\
\square \text { bef-asept. } \\
\square \text { aft-b.f. } \\
\square \text { aft-pat. } \\
\square \text { aft.p.surr. }\end{array}$ & $\begin{array}{l}\square \text { HR } \\
\square \text { HW } \\
\text { O missed } \\
\text { gloves }\end{array}$ & 1 & $\begin{array}{l}\square \text { bef-pat. } \\
\square \text { bef-asept. } \\
\square \text { aft-b.f. } \\
\square \text { aft-pat. } \\
\square \text { aft.p.surr. }\end{array}$ & $\begin{array}{l}\square \mathrm{HR} \\
\square \mathrm{HW} \\
\mathrm{O}_{\text {missed }} \\
O_{\text {gloves }}\end{array}$ & 1 & \begin{tabular}{|}
$\square$ bef-pat. \\
$\square$ bef-asept. \\
$\square$ aft-b.f. \\
$\square$ aft-pat. \\
$\square$ aft.p.surr.
\end{tabular} & $\begin{array}{l}\square \text { HR } \\
\square \text { HW } \\
\text { O missed } \\
\text { gloves }\end{array}$ \\
\hline Opp. & Indication & HH Action & Opp. & Indication & HH Action & Opp. & Indication & HH Action & Opp. & Indication & HH Action \\
\hline 2 & $\begin{array}{l}\square \text { bef-pat. } \\
\square \text { bef-asept. } \\
\square \text { aft-b.f. } \\
\square \text { aft-pat. } \\
\square \text { aft.p.surr. }\end{array}$ & $\begin{array}{l}\square \text { HR } \\
\square \text { HW } \\
\text { O missed } \\
\text { gloves }\end{array}$ & 2 & \begin{tabular}{|l}
$\square$ bef-pat. \\
$\square$ bef-asept. \\
$\square$ aft-b.f. \\
$\square$ aft-pat. \\
$\square$ aft.p.surr.
\end{tabular} & $\begin{array}{l}\square \text { HR } \\
\square \text { HW } \\
\text { O missed } \\
\text { gloves }\end{array}$ & 2 & $\begin{array}{l}\square \text { bef-pat. } \\
\square \text { bef-asept. } \\
\square \text { aft-b.f. } \\
\square \text { aft-pat. } \\
\square \text { aft.p.surr. }\end{array}$ & \begin{tabular}{|l}
$\square \mathrm{HR}$ \\
$\square \mathrm{HW}$ \\
O missed \\
$O$ gloves
\end{tabular} & 2 & \begin{tabular}{|l}
$\square$ bef-pat. \\
$\square$ bef-asept. \\
$\square$ aft-b.f. \\
$\square$ aft-pat. \\
$\square$ aft.p.surr.
\end{tabular} & $\begin{array}{l}\square \text { HR } \\
\square \text { HW } \\
\text { O missed } \\
\text { gloves }\end{array}$ \\
\hline Opp. & Indication & HH Action & Opp. & Indication & HH Action & Opp. & Indication & HH Action & Opp. & Indication & HH Action \\
\hline 3 & $\begin{array}{l}\square \text { bef-pat. } \\
\square \text { bef-asept. } \\
\square \text { aft-b.f. } \\
\square \text { aft-pat. } \\
\square \text { aft.p.surr. }\end{array}$ & $\begin{array}{l}\square \text { HR } \\
\square \text { HW } \\
\text { O missed } \\
\text { gloves }\end{array}$ & 3 & $\begin{array}{l}\square \text { bef-pat. } \\
\square \text { bef-asept. } \\
\square \text { aft-b.f. } \\
\square \text { aft-pat. } \\
\square \text { aft.p.surr. }\end{array}$ & $\begin{array}{l}\square \text { HR } \\
\square \text { HW } \\
\text { O missed } \\
\text { gloves }\end{array}$ & 3 & $\begin{array}{l}\square \text { bef-pat. } \\
\square \text { bef-asept. } \\
\square \text { aft-b.f. } \\
\square \text { aft-pat. } \\
\square \text { aft.p.surr. }\end{array}$ & \begin{tabular}{|l}
$\square$ HR \\
$\square H W$ \\
O missed \\
Ogloves
\end{tabular} & 3 & \begin{tabular}{|l}
$\square$ bef-pat. \\
$\square$ bef-asept. \\
$\square$ aft-b.f. \\
$\square$ aft-pat. \\
$\square$ aft.p.surr.
\end{tabular} & $\begin{array}{l}\square \text { HR } \\
\square \text { HW } \\
\text { O missed } \\
\text { gloves }\end{array}$ \\
\hline Opp. & Indication & HH Action & Opp. & Indication & HH Action & Opp. & Indication & HH Action & Opp. & Indication & HH Action \\
\hline 4 & $\begin{array}{l}\square \text { bef-pat. } \\
\square \text { bef-asept. } \\
\square \text { aft-b.f. } \\
\square \text { aft-pat. } \\
\square \text { aft.p.surr. }\end{array}$ & $\begin{array}{l}\square \text { HR } \\
\square \text { HW } \\
\text { O missed } \\
\text { gloves }\end{array}$ & 4 & $\begin{array}{l}\square \text { bef-pat. } \\
\square \text { bef-asept. } \\
\square \text { aft-b.f. } \\
\square \text { aft-pat. } \\
\square \text { aft.p.surr. }\end{array}$ & $\begin{array}{l}\square \text { HR } \\
\square \text { HW } \\
\text { O missed } \\
\text { gloves }\end{array}$ & 4 & $\begin{array}{l}\square \text { bef-pat. } \\
\square \text { bef-asept. } \\
\square \text { aft-b.f. } \\
\square \text { aft-pat. } \\
\square \text { aft.p.surr. }\end{array}$ & $\begin{array}{l}\square \mathrm{HR} \\
\square \mathrm{HW} \\
O \text { missed } \\
\text { gloves }\end{array}$ & 4 & \begin{tabular}{|l}
$\square$ bef-pat. \\
$\square$ bef-asept. \\
$\square$ aft-b.f. \\
$\square$ aft-pat. \\
$\square$ aft.p.surr.
\end{tabular} & $\begin{array}{l}\square \text { HR } \\
\square \text { HW } \\
\text { O missed } \\
\quad \text { gloves }\end{array}$ \\
\hline Opp. & Indication & HH Action & Opp. & Indication & HH Action & Opp. & Indication & HH Action & Opp. & Indication & HH Action \\
\hline 5 & $\begin{array}{l}\square \text { bef-pat. } \\
\square \text { bef-asept. } \\
\square \text { aft-b.f. } \\
\square \text { aft-pat. } \\
\square \text { aft.p.surr. } \\
\end{array}$ & \begin{tabular}{|l} 
GR \\
口HW \\
O missed \\
O gloves
\end{tabular} & 5 & \begin{tabular}{|l}
$\square$ bef-pat. \\
$\square$ bef-asept. \\
$\square$ aft-b.f. \\
$\square$ aft-pat. \\
$\square$ aft.p.surr. \\
\end{tabular} & $\begin{array}{l}\square \mathrm{HR} \\
\square \mathrm{HW} \\
\mathrm{O}_{\text {missed }} \\
O_{\text {gloves }}\end{array}$ & 5 & $\begin{array}{l}\square \text { bef-pat. } \\
\square \text { bef-asept. } \\
\square \text { aft-b.f. } \\
\square \text { aft-pat. } \\
\square \text { aft.p.surr. } \\
\end{array}$ & $\begin{array}{l}\text { DHR } \\
\square \mathrm{HW} \\
\text { O missed } \\
\text { O gloves }\end{array}$ & 5 & $\begin{array}{l}\square \text { bef-pat. } \\
\square \text { bef-asept. } \\
\square \text { aft-b.f. } \\
\square \text { aft-pat. } \\
\square \text { aft.p.surr. }\end{array}$ & $\begin{array}{l}\text { HR } \\
\square \text { HW } \\
\text { O missed } \\
\text { Ogloves }\end{array}$ \\
\hline Opp. & Indication & HH Action & Opp. & Indication & HH Action & Opp. & Indication & HH Action & Opp. & Indication & HH Action \\
\hline 6 & $\begin{array}{l}\square \text { bef-pat. } \\
\square \text { bef-asept. } \\
\square \text { aft-b.f. } \\
\square \text { aft-pat. } \\
\square \text { aft.p.surr. }\end{array}$ & $\begin{array}{l}\square \text { HR } \\
\square \text { HW } \\
\text { O missed } \\
\text { gloves }\end{array}$ & 6 & $\begin{array}{l}\square \text { bef-pat. } \\
\square \text { bef-asept. } \\
\square \text { aft-b.f. } \\
\square \text { aft-pat. } \\
\square \text { aft.p.surr. }\end{array}$ & $\begin{array}{l}\square \text { HR } \\
\square \text { HW } \\
\text { O missed } \\
\text { gloves }\end{array}$ & 6 & $\begin{array}{l}\square \text { bef-pat. } \\
\square \text { bef-asept. } \\
\square \text { aft-b.f. } \\
\square \text { aft-pat. } \\
\square \text { aft.p.surr. }\end{array}$ & $\begin{array}{l}\square \mathrm{HR} \\
\square \mathrm{HW} \\
\text { O missed } \\
\text { Ogloves }\end{array}$ & 6 & \begin{tabular}{|l}
$\square$ bef-pat. \\
$\square$ bef-asept. \\
$\square$ aft-b.f. \\
$\square$ aft-pat. \\
$\square$ aft.p.surr.
\end{tabular} & $\begin{array}{l}\square \text { HR } \\
\square \text { HW } \\
\text { O missed } \\
\text { gloves }\end{array}$ \\
\hline Opp. & Indication & HH Action & Opp. & Indication & HH Action & Opp. & Indication & HH Action & Opp. & Indication & HH Action \\
\hline 7 & $\begin{array}{l}\square \text { bef-pat. } \\
\square \text { bef-asept. } \\
\square \text { aft-b.f. } \\
\square \text { aft-pat. } \\
\square \text { aft.p.surr. }\end{array}$ & $\begin{array}{l}\text { 口HR } \\
\square \text { HW } \\
\text { O missed } \\
\text { gloves }\end{array}$ & 7 & \begin{tabular}{|l}
$\square$ bef-pat. \\
$\square$ bef-asept. \\
$\square$ aft-b.f. \\
$\square$ aft-pat. \\
$\square$ aft.p.surr. \\
\end{tabular} & $\begin{array}{l}\square \text { HR } \\
\square \text { HW } \\
\text { O missed } \\
\text { gloves }\end{array}$ & 7 & $\begin{array}{l}\square \text { bef-pat. } \\
\square \text { bef-asept. } \\
\square \text { aft-b.f. } \\
\square \text { aft-pat. } \\
\square \text { aft.p.surr. } \\
\end{array}$ & \begin{tabular}{|l}
$\square$ HR \\
$\square$ HW \\
O missed \\
gloves
\end{tabular} & 7 & \begin{tabular}{|l}
$\square$ bef-pat. \\
$\square$ bef-asept. \\
$\square$ aft-b.f. \\
$\square$ aft-pat. \\
$\square$ aft.p.surr.
\end{tabular} & $\begin{array}{l}\square \text { HR } \\
\square \text { HW } \\
\text { O missed } \\
\text { gloves }\end{array}$ \\
\hline Opp. & Indication & HH Action & Opp. & Indication & HH Action & Opp. & Indication & HH Action & Opp. & Indication & HH Action \\
\hline 8 & $\begin{array}{l}\square \text { bef-pat. } \\
\square \text { bef-asept. } \\
\square \text { aft-b.f. } \\
\square \text { aft-pat. } \\
\square \text { aft.p.surr. }\end{array}$ & \begin{tabular}{|l}
$\square$ HR \\
$\square$ HW \\
O missed \\
Ogloves
\end{tabular} & 8 & $\begin{array}{l}\square \text { bef-pat. } \\
\square \text { bef-asept. } \\
\square \text { aft-b.f. } \\
\square \text { aft-pat. } \\
\square \text { aft.p.surr. }\end{array}$ & $\begin{array}{l}\square \text { HR } \\
\square \text { HW } \\
\text { O missed } \\
\text { gloves }\end{array}$ & 8 & $\begin{array}{l}\square \text { bef-pat. } \\
\square \text { bef-asept. } \\
\square \text { aft-b.f. } \\
\square \text { aft-pat. } \\
\square \text { aft.p.surr. }\end{array}$ & \begin{tabular}{|l}
$\square$ HR \\
$\square$ HW \\
O missed \\
Ogloves
\end{tabular} & 8 & \begin{tabular}{|l}
$\square$ bef-pat. \\
$\square$ bef-asept. \\
$\square$ aft-b.f. \\
$\square$ aft-pat. \\
$\square$ aft.p.surr.
\end{tabular} & \begin{tabular}{|l} 
HR \\
$\square$ HW \\
O missed \\
gloves
\end{tabular} \\
\hline
\end{tabular}

Legend: Prof cat = professional category, $\mathrm{D}=$ doctors, $\mathrm{N}=$ nurses, $\mathrm{S}=$ students, Opp. $=$ hand hygiene opportunity, bef.pat. $=$ before patient contact, bef.asept. = before aseptic procedures, aft.b.f. = after body fluid exposure/risk, aft.pat = after patient contact, aft.p.surr. = after contact with patient surroundings, $\mathrm{HH}$ action = hand hygiene action, $\mathrm{HR}=$ hand rubbing with antiseptic, $\mathrm{HW}=$ hand washing, missed $=$ missed opportunity for hand hygiene 